\title{
Validation of a severity index in female urinary incontinence and its implementation in an epidemiological survey
}

\author{
Hogne Sandvik, Steinar Hunskaar, Arnfinn Seim, Ragnar Hermstad, Anita Vanvik, Harald Bratt
}

\begin{abstract}
Study objective-The aim was to validate a simple severity index of female urinary incontinence for subsequent use in an epidemiological survey.

Design-The index was created by multiplying the reported frequency (four levels) by the amount of leakage (two levels). The resulting index value (1-8) was further categorised into slight (1-2), moderate (3-4), and severe (6-8). It was validated against a 48 hour "pad weighing" test. Thereafter, an anonymous postal questionnaire survey was performed and the index was used to assess the severity of the leakage. A question about the impact of incontinence was also included. Setting-The outpatient clinic of the Department of Gynaecology and Obstetrics, Trondheim University Hospital and the rural community of Rissa, Norway.
\end{abstract}

Participants-Altogether 116 incontinent women referred to the clinic by their GP and all 2366 adult women living in Rissa.

Results-The difference in median pad weights between moderate and slight incontinence was $9 \mathrm{~g} / 24 \mathrm{~h}(95 \%$ confidence interval 0-27). The corresponding difference between severe and moderate incontinence was $17 \mathrm{~g} / 24 \mathrm{~h}(95 \% \mathrm{CI} 5-30)$. In the epidemiological survey $29 \cdot 4 \%$ reported urinary incontinence (response rate $77 \%$ ). The prevalence tended to be highest in middle life and old age. Forty six per cent were classified as slight, $27 \%$ moderate, and $27 \%$ severe. There was a strong correlation between severity and impact $(R=0 \cdot 59, p<0 \cdot 001)$.

Conclusion-The severity index may be a useful tool for assessing the severity of female urinary incontinence in epidemiological surveys. It is confirmed that urinary incontinence is very prevalent in adult women, but most should not be regarded as potential patients.

f Epidemiol Community Health 1993; 47: 497-499

Several epidemiological surveys of female urinary incontinence have been conducted over the years. ${ }^{18}$ Not all of these studies cover the complete adult age span, but many authors report a prevalence peak in middle life, followed by a decline, and then a subsequent rise in old age. ${ }^{1-4}$ The actual prevalence numbers vary widely, however, even in the same age group. Prevalence estimates in women aged $45-54$ years vary from approximately $16 \%{ }^{3}$ to $60 \% .^{5}$
Epidemiological surveys of urinary incontinence usually rely on data collected through questionnaires or interviews. Some sort of classification by severity is often used in these studies, ${ }^{1589}$ but the validity of the criteria is uncertain. In addition, different criteria are used by different authors, making comparisons even more difficult.

According to the International Continence Society, urinary incontinence is defined as involuntary loss of urine, which is objectively demonstrable and a social or hygiene problem. ${ }^{10}$ The important aspect of severity is not included in this definiton. There are indications, however, that most incontinent women do not perceive their condition as a major problem. ${ }^{8}$

The overwhelmingly high prevalence numbers often cited represent a challenge for health services. Planning of optimal incontinence care means that the real extent of the problem needs to be carefully investigated. Severity and impact are key issues in this respect.

This study was designed to validate a simple severity index for female urinary incontinence. Furthermore, we wanted to implement this index in an epidemiological survey of the general population, including adult women of all ages and those living in institutions.

\section{Methods}

VALIDATION STUDY

The first part of the study was conducted during the years 1988-92 at the outpatient clinic of the Department of Gynaecology and Obstetrics, Trondheim University Hospital. All women referred by GPs because of urinary incontinence were included. Before proceeding to other diagnostic procedures all patients were interviewed in a standard fashion by a nurse using a structured questionnaire designed for the study.

A severity index was created by multiplying the reported frequency (four levels) by the amount of leakage (two levels) (table I). The resulting index value (1-8) was further categorised into slight (1-2), moderate (3-4), and severe (6-8). Typically, slight incontinence denotes leakage of drops a few times a month, moderate incontinence daily leakage of drops, and severe incontinence larger amounts at least once a week.

A pad weighing test was performed at home by approximately half of the patients. They had been provided with 12 medium sized pads and instructed to wear a preweighed pad day and night during a 48 hour period. They were to change pads when required, but before disposal the pads were reweighed and the weight gain noted. Some women interrupted the pad weighing test after 24 
Table I Questions used to assess the degree or urinary incontinence in women
Table II Severity of the incontinence. "Slight", "moderate" and "severe" grades are based on the severity index. Results of the pad weighing test are given as $g / 24 h$

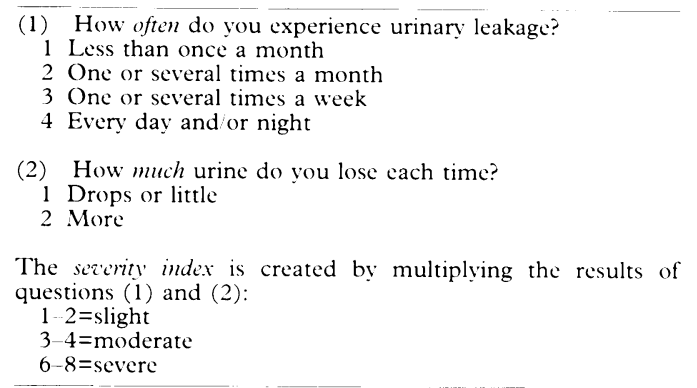

hours, results are therefore presented as amount of leakage (g) per 24 hours. The result of the pad weighing test was considered as the "gold standard" for the severity index (table II).

EPIDEMIOLOGICAI, SLRVEY

The second part of the study was conducted during the spring of 1992 in the rural community of Rissa, Norway. An anonymous questionnaire was mailed to all women aged 20 or more, with a reminder one month later. The target population comprised 2366 women.

The questionnaire covered basic information about age and micturition habits. Those who confirmed urinary incontinence gave further

\begin{tabular}{lccl}
\hline Grade & Mean & Median & Range \\
Slight $(\mathrm{n}=6)$ & 4 & 0 & 0 \\
Moderate $(\mathrm{n}=31)$ & 17 & 9 & 062 \\
Severe $(\mathrm{n}=79)$ & 63 & 30 & 0.559
\end{tabular}

information about duration, frequency, and amount of leakage. The severity of leakage was estimated by using the validated severity index.

The impact of incontinence was measured by the question: "How do you experience your leakage trouble?". The respondents were given the choice of seven answers, ranging from "no problem"(1) to "cannot think of anything worse" (7).

Statistical analyses were done by Mann-Whitney U tests and Spearman's correlation coefficient. The differences in median pad-weights between severity groups were also calculated. In addition, a multiple regression analysis was performed when correlating severity and age with impact. Significance was accepted at the $5 \%$ level $(\mathrm{p}<0.05)$
Prevalence of female urinary incontinence when different "thresholds" for severity are considered

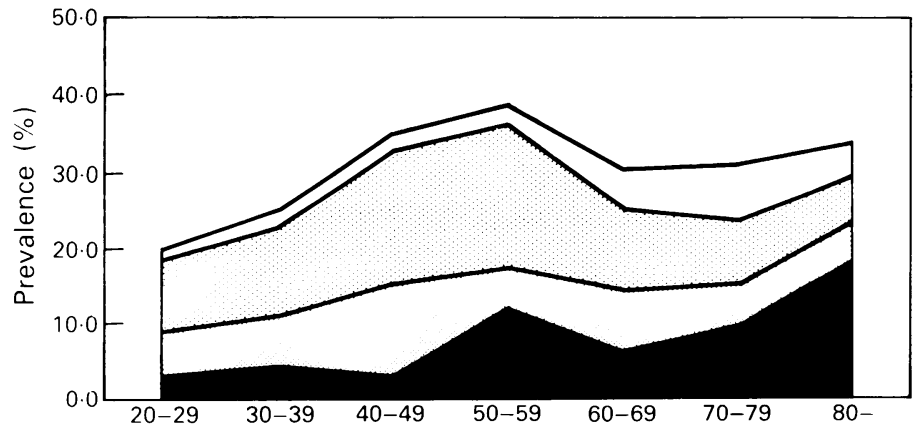

\begin{tabular}{|c|c|c|c|c|c|c|c|}
\hline Unknown & 1.6 & $2 \cdot 3$ & $2 \cdot 0$ & $2 \cdot 3$ & $5 \cdot 4$ & $7 \cdot 0$ & $4 \cdot 1$ \\
\hline Slight & 9.5 & $11 \cdot 6$ & $17 \cdot 7$ & $18 \cdot 6$ & $10 \cdot 7$ & $8 \cdot 6$ & $5 \cdot 9$ \\
\hline Moderate & $5 \cdot 9$ & $6 \cdot 6$ & 11.9 & 5.5 & $8 \cdot 0$ & $5 \cdot 7$ & $5 \cdot 3$ \\
\hline Severe & $2 \cdot 9$ & $4 \cdot 3$ & $3 \cdot 1$ & $11 \cdot 8$ & $6 \cdot 2$ & $9 \cdot 4$ & $18 \cdot 3$ \\
\hline
\end{tabular}

\section{Results}

VALIDATION STLIDY

Pad weighing tests were performed by 116 women. Their mean age was 48 years, median 46 (range 15-83). This subgroup did not differ from the rest with regard to diagnostic distribution, mean age, and mean score on the severity index.

Table II shows the results of the pad weighing test across the three levels of the severity index. Leakage volumes differed significantly both between slight and moderate $(p=0.01)$ and between moderate and severe incontinence $(p<0 \cdot 0001)$. The difference in median pad weights between moderate and slight incontinence was $9 \mathrm{~g} / 24 \mathrm{~h}(95 \%$ CI $0-27)$. The corresponding difference between severe and moderate incontinence was $17 \mathrm{~g} / 24 \mathrm{~h}(5-30)$. The results of the pad-weighing test correlated significantly with reported frequency of leakage $(\mathrm{R}=0.32, \mathrm{p}<0.001)$ and with reported amount of leakage $(\mathrm{R}=0.37, \mathrm{p}<0.001)$. However, when frequency and amount were combined into the severity index, the correlation increased considerably $(R=0 \cdot 48, p<0 \cdot 001)$.

EPIDEMIOLOGICAL SURVEY

In the epidemiological survey a total of 1820 questionnaires were returned $(77 \%)$. Altogether 535 women reported urinary incontinence, giving an overall prevalence of $29 \cdot 4 \%(95 \%$ CI $27 \cdot 3$ $31 \cdot 5 \%)$. Eleven per cent reported a duration of less than one year and $37 \%$ more than five years.

The overall prevalence was highest in the age groups 50-59 and 80+ years. Forty six percent of the cases were classified as slight, $27 \%$ as moderate, and $27 \%$ as severe. Different "thresholds" by increasing severity are illustrated in the figure.

A total of 459 incontinent women answered the question about impact, 445 of whom could also be graded by severity (table III). There was a significant correlation between severity and impact $(\mathrm{R}=0.59, \mathrm{p}<0.001)$. A weaker correlation between age and impact $(\mathrm{R}=0.16, \mathrm{p}=0.01)$ disappeared completely when age and severity were used simultaneously as explanatory variables in a multiple regression analysis

Table III The percentage of women in each severity group who perceived their incontinence as bothersome, or worse

\begin{tabular}{llrl} 
& No & $\%$ & $(95 \% C I)$ \\
\cline { 3 - 4 } Slight & 201 & $4 \cdot 5$ & $(1 \cdot 6 \cdot 7 \cdot 4)$ \\
Moderate & 127 & 21.3 & $(14 \cdot 2-28 \cdot 4)$ \\
Severe & 117 & $55 \cdot 6$ & $(46 \cdot 6-64 \cdot 6)$
\end{tabular}

\section{Discussion}

VALIDATION STUDY

Pad weighing tests are widely used for measuring the severity of incontinence. Inadequate as they may be, they are the best "gold standard" at present. The method used in this study, the 48 hour home test, is less standardised than the one hour laboratory test recommended by the International Continence Society, but is nevertheless considered more valid by patients. ${ }^{11} 12$ It has been suggested that short term tests should be used for diagnostic purposes and long term tests for assessing the severity of incontinence. ${ }^{13} 1.4$ 
Very few attempts have been made to validate anamnestic criteria of severity against pad weighing tests. Frazer et al asked incontinent women to indicate the severity of their incontinence on a $10 \mathrm{~cm}$ visual analogue scale and compared the results with a two hour pad weighing test. ${ }^{15}$ No significant correlation was found.

Hellström et al compared the results of the 48 hour test with subjective assessment by 85 year old men and women, and found that many underestimated their degree of leakage. ${ }^{16}$ These people were asked to classify their incontinence as "slight", "moderate", or "severe". Probably, their subjective, emotional experience was as important as the amount or frequency of leakage.

Our severity index agrees somewhat better with the results of the pad weighing test than the visual analogue scale adopted by Frazer et al. Probably, closed questions with a limited number of possible answers are less subject to emotional bias than vague statements about "severity".

Although considerable overlap between the groups was found, the severity index may be an acceptable tool for quantifying the severity of incontinence in epidemiological surveys. It was to be expected that patients in the general population would be more evenly distributed by the index than the selected patients in the outpatient clinic. Almost half the cases in the general population survey were classified as slight, compared with only $5 \%$ of women from the outpatient clinic. The corresponding figures for severe incontinence were $26 \%$ and $68 \%$ respectively, an indication that hospital patients are indeed highly selected. This selection is logically reflected in different strategies for the management of urinary incontinence in general and gynecological practice. ${ }^{17} 18$

\section{EPIDEMIOLOGICAL SURVEY}

The epidemiological survey confirms that the prevalence of urinary incontinence is very high in adult women, and that there is a prevalence peak in middle life. Furthermore, there is also an obvious shift towards increasing severity with advancing age.

Most women identified as incontinent in epidemiological surveys have only occasional leakage of small amounts of urine. ${ }^{158}$ Our definition of slight incontinence implies leakage of drops less than once a week, and many of these women would probably object to being labelled "incontinent" at all. It seems more fruitful to direct our attention to those who have more than minimal leakage, and for this purpose a valid severity index may be useful.

Other authors have used different definitions of regular, moderate, and severe incontinence; prevalence numbers varying between $8.5 \%$ and $16 \cdot 7 \%^{12}+58$ Lagro-Janssen et al investigated women aged 50 to 65 years, and found that $5 \%$ were worried about their incontinence. ${ }^{8}$ Sommer et al found that $6 \%$ of women aged 20 to 79 were troubled by incontinence. ${ }^{7}$ Holst et al reported that $4 \%$ of all adult women had moderate/severe incontinence that interfered with their social or domestic life. ${ }^{4}$ Elving et al found that during one year $10 \%$ of women aged 30 to 59 experienced incontinence and perceived this as a social or hygiene problem. ${ }^{6}$

If only those with moderate and severe incontinence are considered, and including only those who are bothered by their leakage, our results indicate that approximately $20 \%$ of the incontinent women (that is, $6 \%$ of all adult women) are potential patients. Nevertheless, these prevalence estimates far exceed the capacity of the specialised health service and should be regarded as a challenge for the primary health care.

\section{Conclusion}

The severity index may be a useful tool for assessing the severity of female urinary incontinence in epidemiological surveys. Urinary incontinence is very prevalent in adult women, but most should not be regarded as potential patients for their health services.

1 Thomas TM, Plymat KR, Blannin J, Meade TW. Prevalence of urinary incontinence. $B M 17$ 1980; 281: 1243-5.

2 Yarnell JW, Voyle GJ, Richards CJ, Stephenson TP. The

prevalence and severity or urinary incontinence in women. $\mathcal{f}$ prevalence and severity or urinary incontinence
Epidemiol Community Health 1981; 35: 71-4.

3 Fall M, Frankenberg S, Frisén M, Larsson B, Petrén M. 456,000 Swedes may have urinary incontinence. Only every fourth person seeks help for the disorder (in Swedish). Läkartidningen 1985; 82: 2054-6.

4 Holst K, Wilson PD. The prevalence of female urinary incontinence and reasons for not seeking treatment. $\Lambda^{\top} Z$ Med F 1988; 101: 756-8.

5 Jolleys JV. The reported prevalence of urinary symptoms in women in one rural general practice. Br f Gen Pract 1990; 40: $335-7$.

6 Elving LB, Foldspang A, Lam GW, Mommsen S. Descriptive epidemiology of urinary incontinence in 3,100 women age 30-59. Scand f Urol Nephrol 1989; 125 (suppl): women

7 Sommer P, Bauer T, Nielsen KK, et al. Voiding patterns and prevalence of incontinence in women. A questionnaire prevalence of incontinence in won
survey. $B r f$ Urol 1990; 66: 12-5.

8 Lagro-Janssen TLM, Smits AJ, van Weel C. Women with urinary incontinence: self perceived worries and general practitioners' knowledge of problem. Brf Gen Pract 1990; 40: $331-4$

9 Simeonova Z, Bengtsson C. Prevalence of urinary incontinence among women at a Swedish primary health care centre. Scand $\mathcal{F}$ Prim Health Care 1990; 8: 203-6.

10 Abrams P, Blaivas JG, Stanton SL, Andersen JT. The standardisation of terminology of lower urinary tract function. The International Continence Society Committee on Standardisation of Terminology. Scand $\mathcal{F}$ Urol Nephrol 1988; 114 (suppl): 5-19.

11 Jakobsen H, Vedel P, Andersen JT. Objective assessment of urinary incontinence: An evaluation of three different pad-weighing tests. Neurourology and Urodynamics 1987; 6: 325-30.

12 Kralj D. Comparative study of pad tests-reliability and repetitiveness. Neurourology and Urodynamics 1989; 8: 305-6.

13 Petros PP, Ulmsten U. An analysis of rapid pad testing and the history for the diagnosis of stress incontinence. Acta the history for the diagnosis of stress
Obstet Gynecol Scand 1992; 71: 529-36.

14 Victor A. Pad weighing test-a simple method to quantitate urinary incontinence. Ann Med 1990; 22: 443-7.

15 Frazer MI, Haylen BT, Sutherst JR, The severity of urinary incontinence in women. Comparison of subjective and objective tests. $B r \mathcal{F}$ Urol 1989; 63: 14-5.

16 Hellström L, Ekelund P, Larsson M, Milso MI. A comparison between experienced and objectively demonstrated urinary leakage in 85-year old men and women. Scand fournal of Caring Sciences 1991; 5: 17-21.

17 Sandvik H, Hunskaar S, Eriksen BC. Management of urinary incontinence in women in general practice: actions taken at the first consultation. Scand $\mathcal{7}$ Prim Health Care 1990; 8: 3-8

18 Eriksen BC, Sandvik H, Hunskaar S. Management of urinary incontinence in gynecological practice in Norway. Acta Obstet Gynecol Scand 1990; 69: 515-9. 